\title{
Thin films of boron nitride grown by CVD
}

\author{
A RATNA PHANI \\ Physical and Inorganic Chemistry Division, Indian Institute of Chemical Technology, \\ Hyderabad 500007, India \\ MS received 11 May 1993; revised 15 March 1994

\begin{abstract}
For the first time, thin films of boron nitride were deposited by chemical vapour deposition on to polished silicon and other metal substrates using the inorganic compound $\mathrm{H}_{3} \mathrm{BNH}_{3}$ (aminodiborane) and ammonia as carrier gas. The substrate temperature was varied from 400 to $600^{\circ} \mathrm{C}$. The films were chemically inert and adherent to the substrates. The FTIR spectrum of the film showed B-N-B absorption at $800 \mathrm{~cm}^{-1}$, B-N stretching at $1056 \mathrm{~cm}^{-1}$, and also a weak absorption at $1340 \mathrm{~cm}^{-1}$ corresponding to $\mathrm{B}-\mathrm{N}-\mathrm{B}$ bending vibration. Deposited films also exhibited $\mathrm{X}$-ray diffraction pattern with interplanar spacing with (002) plane of hexagonal boron nitride.
\end{abstract}

Keywords. Aminodiborane; chemical vapour deposition; boron nitride.

\section{Introduction}

Boron nitride (BN) possesses high thermal stability, is chemically stable in aggressive media and can exist as cubic BN (C-BN), hexagonal BN (h-BN) and rhombohedral $B N(r-B N)$. The crystalline form of $c-B N$ is known as an abrasive. Thin amorphous nitride films are used in microelectronics as a source of boron diffusion in silicon. Hexagonal $\mathrm{BN}$ is known to form corrosion-resistant and insulating film which can be used in a high-temperature molten salt or corrosive gaseous environment. A relatively high resistance of the film to thermal shock also gives possibility of its use as a refractory container where rapid heating or cooling is required. Chemical vapour deposition (CVD) of $\mathrm{BN}$ has been studied by many investigators using thermal decomposition of $\mathrm{BCl}_{3}$ using $\mathrm{NH}_{3}$ (Powell et al 1962; Sano and Aoki 1981; Motojma et al 1989). Apart from CVD, many other techniques to deposit c-BN films have been investigated. These include activated reactive evaporation with a gas activation nozzle (Inagawa et al 1987), arc-like plasma-enhanced ion plating (Ikeda et al 1991), ion beam deposition (Ikeda 1992), plasma chemical transport (Saitoh and Yarbrough 1991a), electron beam-assisted hot filament CVD (Chaudhari et al, submitted), and r.f. plasma CVD (Saitoh and Yarbrough 1991b). However, the obtained films consist of c-BN and h-BN. The content of c-BN phase in the film was not very high. Of all the techniques employed so far, CVD is the most common and involves formation from reactive compounds by thermal means. These techniques generally require a high substrate temperature. For $\mathrm{BN}$ deposition by the thermal $\mathrm{CVD}$ technique handling of toxic and hazardous starting materials such as $\mathrm{B}_{2} \mathrm{H}_{6}, \mathrm{BCl}_{3}, \mathrm{BBr}_{3}$, etc. is often required. In our present investigation, $\mathrm{BN}$ films were deposited on polished Si wafers and Ni substrates by using a single-source precursor containing both boron and nitrogen. 


\section{Experimental procedure}

Aminodiborane (ADB), the single-source precursor, is a solid that can be volatilized under vacuum. This material is prepared by treating sodium borohydride $\left(\mathrm{NaBH}_{4}\right)$ with ammonium carbonate in the presence of tetrahydrofuran (THF) solvent for about $14 \mathrm{~h}$ in $\mathrm{N}_{2}$ atmosphere. The contents are filtered to obtain $\mathrm{H}_{3} \mathrm{BNH}_{3}$ which is slowly soluble in THF. THF is distilled out to obtain crystalline white solid of $\mathrm{H}_{3} \mathrm{BNH}_{3}$.

BN was deposited by CVD using ADB with ammonia as carrier gas in a flow system. A schematic diagram of the apparatus is shown in figure 1 . At the centre of the horizontal quartz reactor, substrates were kept slanted and located downstream of the $\mathrm{NH}_{3}$ outlet. The inorganic compound ADB was kept outside the furnace and was heated by using a coil heater (up to $200^{\circ} \mathrm{C}$ slowly). The distance between the substrates and the source was $5 \mathrm{~cm}$. Silicon substrates used in the present study were degreased with warm isopropyl alcohol, washed with deionized water and etched with $\mathrm{HF}$ acid followed by rinsing with running deionized water, and finally blown dry with $\mathrm{N}_{2}$ and quickly loaded into the reactor. Ni substrates were cleaned similarly except that $\mathrm{HF}$ acid was replaced with $\mathrm{HCl}$.

Prior to reaction, the reaction tube was flushed with $\mathrm{N}_{2}$ and the substrates placed in the deposition zone and heated to the deposition temperature at a pressure -of 1 mbar. The vapours of $\mathrm{ADB}$ were transported by ammonia as carrier gas at a flow rate of $40 \mathrm{ml} / \mathrm{min}$, the total internal pressure being adjusted to $500 \mathrm{mbar}$. The deposition was carried out for $12 \mathrm{~h}$ after which the substrates were slowly brought to room temperature under $\mathrm{N}_{2}$ atmosphere and finally stored in vacuo. The films were characterized by FTIR (Nicolet 740), XRD (Phillips PW 1140 with FeK radiation) and SEM (Hitachi S 520).

\section{Results and discussion}

\subsection{FTIR spectra}

Films deposited on polished silicon wafer at two different temperatures were studied by FTIR. The distinct features of the spectrum of samples deposited at $500^{\circ} \mathrm{C}$ are strong asymmetric bands near $800 \mathrm{~cm}^{-1}$ and $1056 \mathrm{~cm}^{-1}$ and weaker bands at $1312 \mathrm{~cm}^{-1}$. The positions of these absorption peaks were practically the same for the

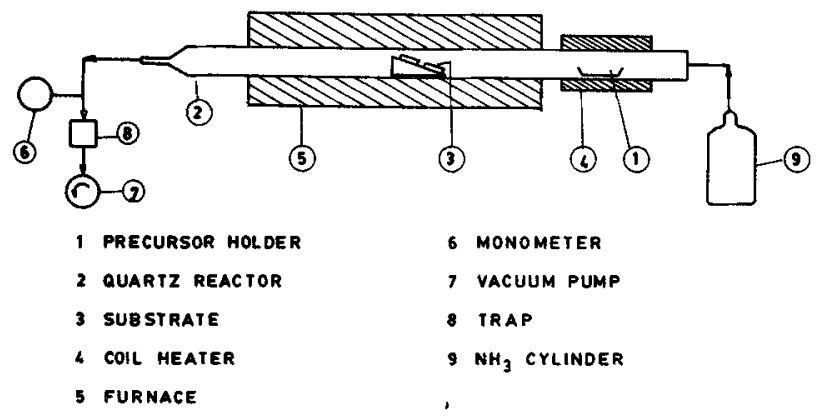

Figure 1. Schematic diagram of CVD reactor for BN deposition. 

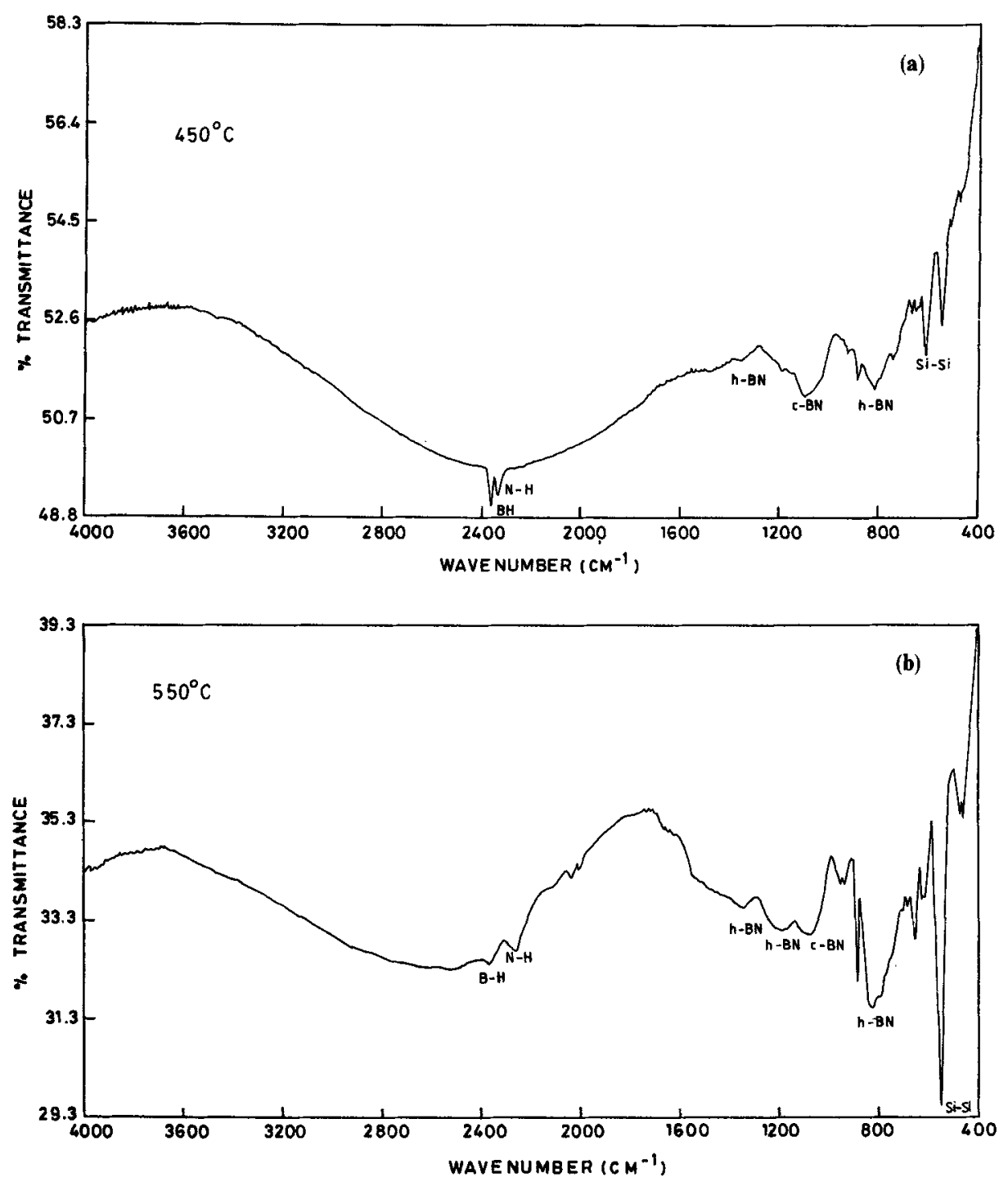

Figure 2. FTIR spectra of BN films on Si.

samples deposited at $450^{\circ} \mathrm{C}$, as shown in figure 2. FTIR absorption measurements on BN films have been published by several workers (Takahashi et al 1979; Paul et al 1990; Bath et al 1991; Maya and Haugh 1991). The two peaks observed at $1056 \mathrm{~cm}^{-1}$ and $800 \mathrm{~cm}^{-1}$ correspond to those of c-BN and h-BN respectively. The strong peak at $800 \mathrm{~cm}^{-1}$ corresponds to $\mathrm{B}-\mathrm{N}$ bond stretching, and the weaker band at $1312 \mathrm{~cm}^{-1}$ is attributed to B-N-B bending. Small peaks at $2430 \mathrm{~cm}^{-1}$ have been assigned to $\mathrm{N}-\mathrm{H}$ stretching mode, while no peaks were observed at $3300 \mathrm{~cm}^{-1}$ for $\mathrm{O}-\mathrm{H}$ bending.

In the light of the above we conclude that, in our case, the deposited BN films contain both the phases of $\mathrm{BN}$, i.e. h-BN and c-BN. It is also noteworthy that films deposited on silicon substrates at $550^{\circ} \mathrm{C}$ and $450^{\circ} \mathrm{C}$ show absorption at $624 \mathrm{~cm}^{-1}$ 
due to $\mathrm{Si}-\mathrm{Si}$ bond vibration along with peaks of very weak intensities at 544,878 and $1168 \mathrm{~cm}^{-1}$. Besides the above, we have also analysed the unreacted compound by FTIR, which shows peaks at 790 and $1400 \mathrm{~cm}^{-1}$ attributed to B-N stretching, and 1045 and $1575 \mathrm{~cm}^{-1}$ attributed to $\mathrm{B}-\mathrm{N}-\mathrm{B}$ bending.

\subsection{XRD characteristics}

$\mathrm{X}$-ray diffractograms of $\mathrm{BN}$ films deposited at $550^{\circ} \mathrm{C}$ on silicon and nickel substrates are shown in figure 3. The XRD of $\mathrm{BN} / \mathrm{Ni}\left(\right.$ at $550^{\circ} \mathrm{C}$ ) film shows distinct peaks due
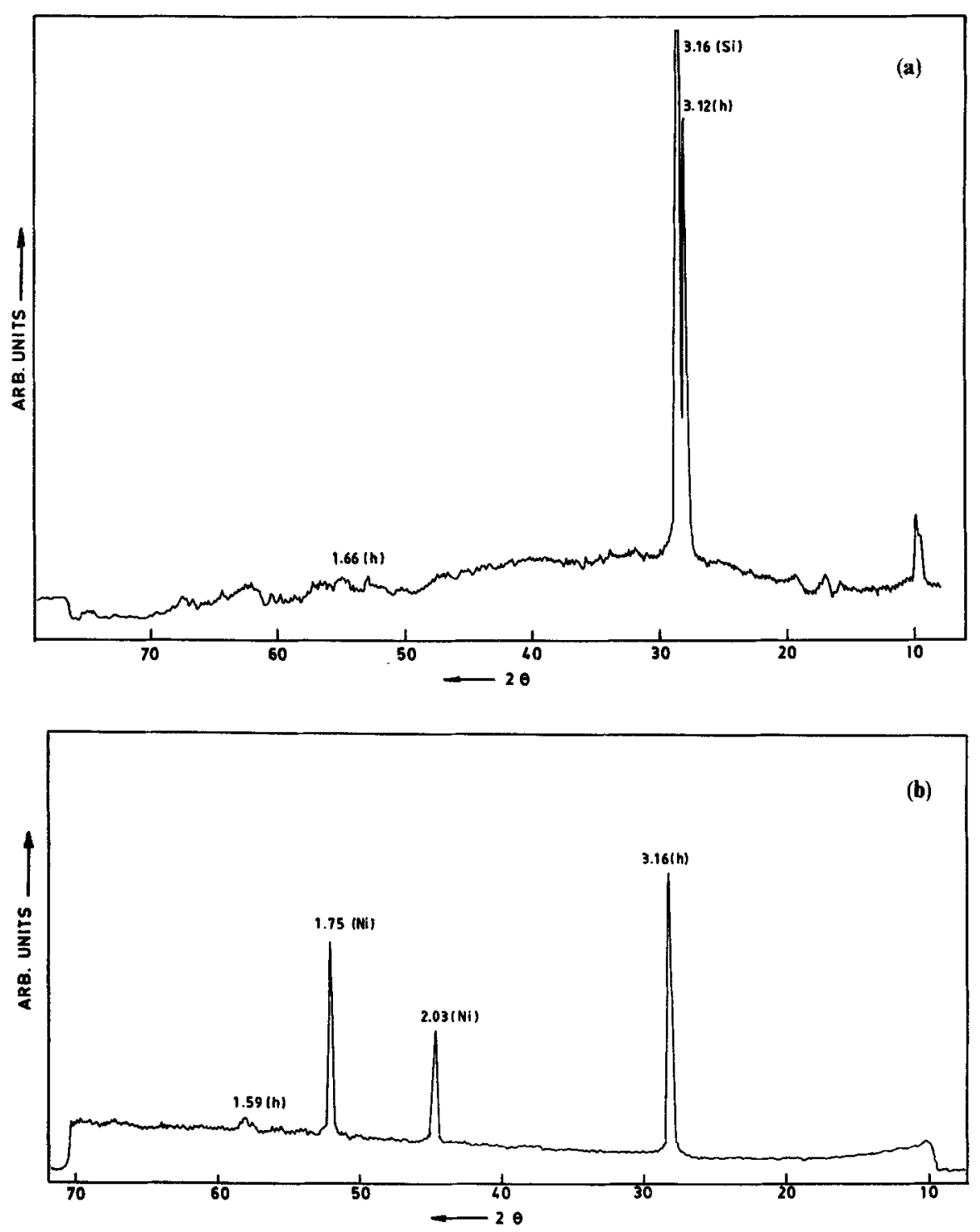

Figure 3. X-ray diffractograms of BN films: (a) BN/Si at $550^{\circ} \mathrm{C}$; (b) $\mathrm{BN} / \mathrm{Ni}$ at $550^{\circ} \mathrm{C}$. 

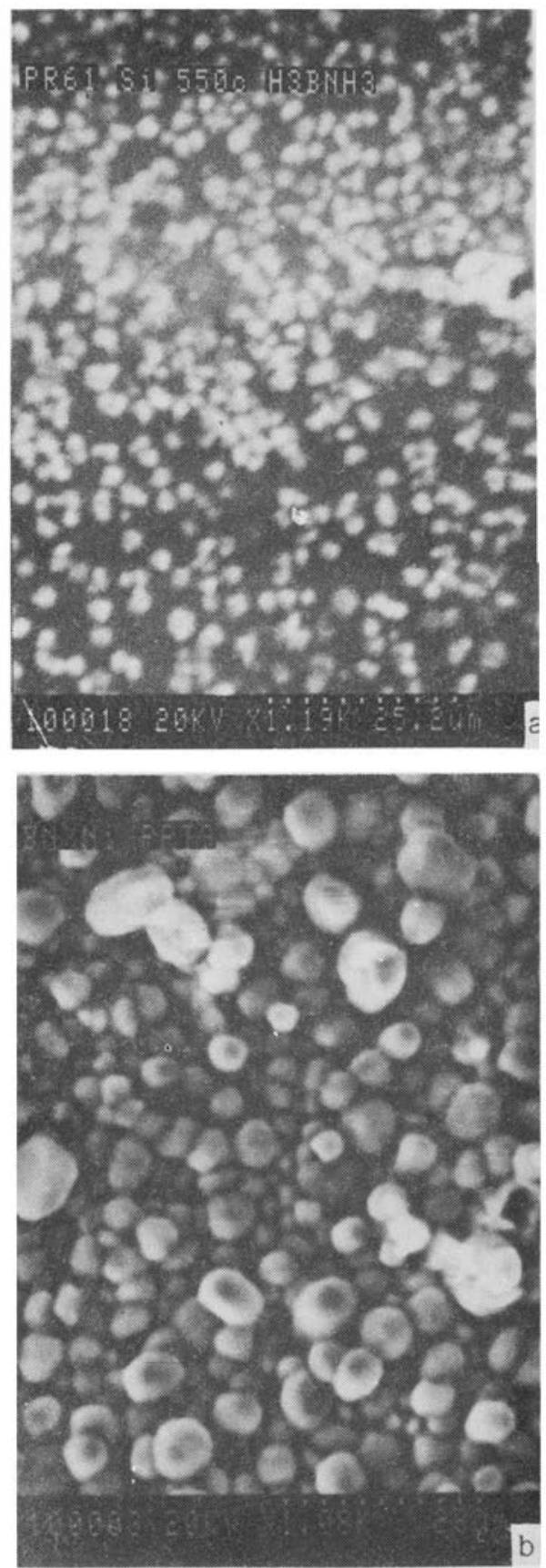

Figure 4. Scanning electron micrographs of $\mathrm{BN}$ films deposited on (a) $\mathrm{Si}$ and (b) $\mathrm{Ni}$ at $550^{\circ} \mathrm{C}$. 
to h-BN at $d=3.33 \AA$. Similarly the XRD pattern of BN/Si film shows h-BN peaks at $d=3 \cdot 12 \AA$ and $d=1.66 \AA$. In both the above cases, peaks due to $\mathrm{Ni}$ and $\mathrm{Si}$ are observed, which suggest that the thickness of the $\mathrm{BN}$ films is low. However, the peak at $d=3.33 \AA$, corresponding to (002) plane of $100 \%$ relative intensity in h-BN, is present in the case of $\mathrm{Si} / \mathrm{Ni}$ films obtained by us. It suggests that FTIR information on h-BN present in film deposited on $\mathrm{Si}$ as described earlier may correspond largely to its amorphous nature. An XRD pattern of the precursor collected from the boat after the reaction was also taken. The XRD pattern shows distinct peaks at angles corresponding to lattice constant values of $3.08 \AA$ and $2.202 \AA$ representing the (002) and (100) crystallographic planes of $h-B N$ and c-BN respectively.

\subsection{Surface morphology}

SEM of deposited films is shown in figure 4. The films deposited at $550^{\circ} \mathrm{C}$ show highly crystalline $\mathrm{BN}$ particles. The nucleation of the crystal grains has been so initiated that they look like pebbles.

\section{Conclusions}

BN films were deposited by CVD from aminodiborane at $550^{\circ} \mathrm{C}$ in the presence of $\mathrm{NH}_{3}$ gas. FTIR and XRD data reveal the presence of BN phases. SEM shows well-formed crystallites with uniform size for films grown on $\mathrm{Si}$ and $\mathrm{Ni}$ substrates at $550^{\circ} \mathrm{C}$. Further investigations on structure and other parameters are being carried out.

\section{Acknowledgement}

The author wishes to thank Dr V J Rao for his constant encouragement and many helpful discussions.

\section{References}

Bath A, Vander Putt P J, Becht J G M, Schooman J and Lepley B 1991 J. Appl. Phys. 704366 Chaudhari G N, Phani A R, Manorama S and Rao V J J. Phys. D. (submitted)

Ikeda T 1992 Appl. Phys. Letts. 61786

Ikeda T. Satcu T and Satch H 1991 Surf. Coating Tech. 5033

Inagawa K, Watanabe K, Ohsone H, Saitoh K and Itoh A 1987 J. Vac. Sci. Tech. A5 2696

Maya L and Haugh L R $1991 \mathrm{~J}$. Am. Ceram. Soc. 74406

Motojma S, Hotta H and Gota K 1989 Mater. Lett. 8457

Paul T K, Battacharya P and Bose D N 1990 Appl. Phys. Letts. 562648

Powell C F, Oxley J H and Blocher J M J 1962 Vapour deposition (New York: Wiley) p. 663

Saitoh H and Yarbrough W A 1991a Appl. Phys. Letts. 582281

Saitoh H and Yarbrough W A 1991 b Appl. Phys. Letts. 582482

Sano M and Aoki M 1981 Thin Solid Films 83247

Takahashi T, Itoh H and Takeuchi A 1979 J. Cryst. Growth 47295 